\title{
Uma Trama para Schnittke: Considerações Narrativas para o Concerto Grosso n.1
}

Bruno Milheira Angelo

(UFRGS)

Resumo: O presente trabalho é um ensaio sobre a narratividade musical dividido em duas partes: a primeira constitui uma revisão crítica da literatura acadêmica relacionada ao assunto, donde são extraídos fatores de relevância da narrativa para a musicologia analítica; já na segunda parte proponho uma concepção narrativa para o Concerto Grosso n.1 (1977) de Alfred Schnittke, através de uma análise que tome em consideração as constatações da primeira parte. As problemáticas aqui abordadas partem de questionamentos sobre as potenciais contribuições da narratividade na compreensão musical, bem como o âmbito em que esta ocorre na perspectiva semiológica tripartite de J. J. Nattiez.

Palavras-chave: Narratividade Musical; Análise Musical; Semiologia Musical Tripartite; Alfred Schnittke.

\section{A PLOT FOR SCHNITTKE: NARRATIVE CONSIDERATIONS FOR THE CONCERTO GROSSO N.1}

Abstract: The present work is an essay on musical narrativity divided in two sections: the first provides a critic revision of academic literature on the issue, from which are extracted some relevant factors of narrative in musical analysis; the second section proposes a narrative approach to the Concerto Grosso n.1 (Alfred Schnittke, 1977) by means of an analysis that considers the points made in the first section. The considerations made here question potential contributions of narrativity to musical comprehension, as well as where it stands regarding the tripartite semiological perspective of J. J. Nattiez.

Keywords: Musical Narrativity; Musical Analysis; Tripartite Musical Semiology; Alfred Schnittke 


\section{Narratividade em Música}

O estudo das relações entre música e processos narrativos tem sido objeto de atenção crescente entre musicólogos desde o fim dos anos 1980 , principalmente no tocante à análise musical de obras do século XIX. Esse tipo de abordagem busca justificar-se, no caso específico da música tonal, através de uma premissa histórica que coloca a narratividade como intrínseca aos processos poiéticos e/ou estésicos que envolvem determinadas obras musicais ${ }^{1}$. Por outro lado, tais estudos da narrativa musical - apesar de geralmente estarem envolvidos com um repertório restrito - não lhe impõem limites históricos ou estilísticos, buscando antes chegar a reflexões abrangentes e renovadoras do pensamento musicológico, tendência que pode ser percebida na diversidade e quantidade de pesquisadores e perspectivas analíticas voltados ao assunto. Segundo Jean-Jacques Nattiez:

(...) Até alguns anos atrás, considerei a noção de conto ou narração musical como sendo simplesmente outra metáfora pela qual a linguagem humana, com seus meios escassos, tentava definir a especificidade do desenrolar musical no tempo. Mas assim que alguns excelentes autores no campo da análise e crítica musical tomam essa metáfora a sério, até mesmo a pessoa mais resistente a aproximações semânticas deve convir que onde há fumaça, há fogo. (Nattiez, 1990a, p. 241)

A associação entre música e processos narrativos por parte de ouvintes ou compositores não é recente, mas remonta pelo menos ao século XIX (Abbate, 1991, p. 24). As investigações atuais, entretanto, tomam por base teorias semióticas e literárias do século $X X$ na tentativa de atribuir um conteúdo semântico ao texto musical, propondo-se questões como: (1) porque

\footnotetext{
1 Como exemplo dum posicionamento estésico cite-se Eero Tarasti: “Chopin (...) viveu numa época que percebia o conteúdo narrativo de obras musicais como o nível essencial de sua significação." (Tarasti, 1994, p. 138). No tocante às estratégias poiéticas, Márta Grabócz assim define a "forma evolutiva" em Franz Liszt: "Essas estruturas, concebidas de maneira original, não obedecem nenhuma estrutura ou forma musical histórica, mas esboçam um conteúdo narrativo específico através de seus elementos significantes. Mesmo as transformações em nível de tonalidade estão concebidas de acordo com os estados da narração." (Grabócz, 1986, p. 106)
} 
determinadas músicas incitam processos narrativos? (Álmen 2008, Hatten, 1991); (2) Se existe uma narratividade em música, em que âmbito do fenômeno musical ela ocorre? (Nattiez 1990a e 1990b, Abbate, 1991); e (3) Qual a contribuição da narratividade musical aos processos analíticos já existentes? (Kramer 1991, Karl 1997. Mickznik 2001, Klein 2004). Em todo o caso, como primeiro passo para avançar-se sobre essas perguntas impõe-se uma questão anterior, a saber, a própria definição da narratividade. Ao partirem de concepções distintas de narrativa - que são, como veremos, ênfases em diferentes especificidades do conceito - os autores acabam condicionando seu raciocínio a caminhos nem sempre relacionados entre si, às vezes completamente opostos.

Uma primeira distinção a ser feita no conceito de narrativa, enfatizada por Carolyn Abbate em seu livro Unsung Voices: Opera and Musical Narrative in the Nineteenth Century (1991), é a própria presença do narrador, o qual necessariamente transcende os fatos narrados e os relata em tempo pretérito. Essa condição traz consigo restrições consideráveis na aplicação do conceito em música, já que esta, segundo Abbate, possui uma característica "fundamental e terrível; ela não é basicamente diegética, mas mimética. (...) Ela prende o ouvinte no presente da experiência e no pulso passante do tempo, de onde ele não pode escapar" (Abbate, 1991, p. 53). Sendo assim, a existência de uma narrativa intrinsecamente musical é rara, restrita a casos em que a música assume outra voz - a do narrador - através de certos gestos historicamente estabelecidos na ópera, com algumas ressonâncias na música instrumental do século XIX (Abbate, 1991, p. 19). A análise, feita pela autora, de $O$ Aprendiz de Feiticeiro (P. Dukas)² é emblemática nesse sentido, pois considera apenas os últimos compassos da peça como sendo de fato uma narrativa, apesar de tratar de uma obra amplamente programática.

Outra precaução contra o potencial narrativo da música é considerada por Nattiez, que chama atenção para a indefinição da semântica musical em relação à literária - que é a origem do conceito de narrativa ${ }^{3}$. Mais

\footnotetext{
${ }^{2}$ What the Sorcerer Said, in Unsung Voices (Abbate, 1991).

${ }^{3}$ Tal posição é corroborada por Byron Álmen: "existe um risco de se super-interpretar obras musicais para torná-las eventos mais literários, como por exemplo, atribuindo-lhes um grau elevado de especificidade referencial" (Almén, 2008, p. 13).
} 
especificamente, sob a perspectiva de sua semiologia tripartite, há somente sujeitos na música, jamais predicados. Sendo assim, não se estabeleceria em sua imanência uma equivalência para a narrativa literária. O autor ainda exemplifica:

Quando escuto uma marcha na segunda sinfonia de Mahler, imagino que tem a ver com algum grupo de pessoas, mas não sei quais pessoas. A marcha pode aproximar-se ou afastar-se; duas procissões podem se cruzar (como em Three Places in New England, de Ives), mas eu não sei de onde eles vêm ou para onde estão indo. (Nattiez, 1990b, p. 128)

Portanto, a existência de uma narrativa seria produto do ouvinte, o qual atribui à obra musical informações que Ihes são externas a fim de compreender ou dar continuidade à sucessão de eventos sonoros ${ }^{4}$. Por outro lado, tal argumento abre um viés de comparação explícita com a linguagem verbal, pelo qual se deve considerar uma contraposição de Raymond Monelle, contemporânea ao artigo de Nattiez:

O tema musical ocupa um lugar especial, uma espécie de sintagma semântico, exclusivo em cada obra musical. Não há nada semelhante na linguagem ou narrativa [literária], aparentemente por que a relação entre semântica e sintática está diferentemente situada na música. Por esta razão, o som musical - o nível fonológico de manifestação - é inseparável do nível semântico. (Monelle, 1991, p. 87)

É nesse terreno pouco delimitado entre o musical e o extra musical que, a meu ver, se situam outros estudos sobre a narratividade musical, abrindo espaço para abordagens mais amplas desse conceito. Por exemplo, a atribuição de agentes ao discurso sonoro, em forma de personagens ou estados psicológicos de uma entidade abstrata, é explorada de maneiras distintas em análises de, entre outros, Hatten (1991), Maus (1991), Tarasti (1994), Karl (1997) e Almén (2008). $\mathrm{Na}$ identificação de agentes ou atores musicais está implicado o inevitável conflito entre eles, que por sua vez está ligado diretamente com a forma musical. Tarasti (1994, p. 154-180), em sua análise da Balada n. 1 de Chopin, evidencia esse

${ }^{4}$ Ainda Nattiez: "Nunca se poderá sobre-enfatizar a diferença entre música, e música como objeto de meta-linguagens por ela geradas" (1990b, p. 128). 
conflito logo em suas primeiras "conclusões gerais": "[a peça] envolve uma luta entre dois atores temáticos, o motivo da valsa e o motivo quasiparlando, o qual em seguida ameaça com tornar-se preponderante" (Tarasti, 1994, p. 155). Essa descrição sucinta, já em si narrativa, é uma síntese formal da Balada, na qual o autor deixa implícita também a síntese do que para ele é o ponto nevrálgico no conteúdo da peça: a trama de um conflito $^{5}$. A esse respeito, e um pouco mais ambicioso, Gregory Karl afirma que:

Considerar que uma obra musical é organizada por uma trama significa: (1) que alguns de seus elementos podem ser entendidos como representantes de agentes quase-sencientes e suas ações, e (2) que a totalidade dessas ações forma uma unidade completa e coerente, co-extensiva e inclusiva da totalidade do desenrolar musical. (Karl, 1997, p. 16)

Se eliminarmos da afirmação acima o item (1), chego ao que considero como aproximações mais gerais da narrativa musical, ou seja, que abstraem do conceito unicamente sua implicação de causa e efeito para com ela criar histórias sobre o texto musical. Esse tipo de abordagem, em sua ampla generalização, beira a transcendência da narratividade, ao ponto de podermos dizer, junto com Michael Klein, que "quase todos os textos musicológicos fazem uso de metáforas para contar histórias sobre estruturas" (Klein, 2004, p. 144). Para esse autor, preocupado com as relações intertextuais na música e sua rede potencialmente infinita de significações, a narrativa é um meio efetivo de ligar essas relações em uma "unidade aparente" (2004, p. 108-136). Além disso, em sua análise da sinfonia n.4 de Lutoslawski, o autor concebe uma narrativa trágica com base nas próprias referências intertextuais e na teoria semiológica de tópicos (cf. Agawu, 1991), ou seja, uma narrativa feita de outras narrativas, com referência particular à Balada nº 4 de Chopin ${ }^{6}$.

\footnotetext{
5 "A Atorialidade (Actoriality) conforma um dos níveis mais pertinentes e mais claramente explícitos da obra". (Tarasti, 1994, p. 161)

${ }^{6}$ Além de Chopin, o autor busca referências em Prokofiev, Mahler e Beethoven, ou em outras obras do próprio Lutoslawski, como Musique Funèbre, o Concerto para Piano e Chain 1 (Klein, 2004, p. 134).
} 


\section{Sobre o Potencial da Narratividade Musical}

É possível ressaltar, dentre os estudos mencionados, uma característica comum à grande parte dos musicólogos voltados ao assunto: o desejo de conceder à música uma compreensão sintetizadora de seus elementos que, através do princípio de causalidade, busque ainda atribuir-lhe um conteúdo semântico desde uma perspectiva geral. Esse desejo é assim expressado por Byron Álmen:

Eu vejo a narrativa como articuladora das dinâmicas e possíveis resultantes de conflitos e interações entre elementos, gerando significado para a sucessão temporal de eventos, e coordenando esses eventos num todo interpretativo. (Almén, 2008, p. 13)

Nesse sentido, a narrativa é uma ferramenta complementar e nem sempre relevante em sua aplicação, ou seja, sua efetividade depende da música a que pretende somar-se. Em todo o caso, seguindo Abbate e Nattiez, não vejo motivo para se buscar uma narrativa na imanência musical; mas apesar da aparente desesperança do último em relação ao assunto, creio que sua posição é um ponto de partida fundamental para um avanço coerente sobre a questão:

Se, ao escutar música, sou tentado pelo 'impulso narrativo', isso acontece porque, no nível estritamente musical do discurso, eu reconheço retornos, expectativas e resoluções, mas do quê eu não sei. Logo tenho o desejo de completar com palavras o que a música não diz porque não é de sua natureza semiológica dizê-lo. (Nattiez, 1990a, p. 245)

A narrativa musical, portanto - e usando os termos da semiologia tripartite de Nattiez -, pode ocorrer desde os níveis poiético ou estésico, neste último caso carregando consigo a subjetividade do ouvinte/intérprete/analista. Seu potencial associativo de significações é pressentido inclusive por Nattiez:

Já que a música possui certa capacidade de evocação imitativa, é possível que ela imite a aparência de uma narração sem que nunca saibamos o conteúdo de seu discurso, e essa influência dos modos narrativos pode contribuir para a transformação da forma musical. (Nattiez, 1990a, p. 257) 
Sem embarcarmos em desvarios hermenêuticos, podemos afirmar que o interesse da narratividade musical depende de três fatores:

1. O grau de fundamentação da narrativa na música ${ }^{7}$ : basicamente, toma-se por premissa que os elementos relevantes de uma devem encontrar equivalências igualmente importantes em outra; neste ponto percebe-se mais claramente a interdependência entre a concepção narrativa e as ferramentas analítico- musicais existentes.

2. A relevância do conteúdo atribuído à música através da narrativa, evitando o desgaste de lançar mão de um conceito polêmico, como visto, para produzir afirmações factíveis dentro de uma perspectiva musicológica convencional. Este ponto mantém vivo um questionamento feito, entre outros, por Vera Micznik (2001, p. 198), e que, graças às divergências quanto ao emprego do conceito de narratividade em musica, ainda não foi esclarecido de forma definitiva. A meu ver, a eficiência de uma metodologia analítica baseada na analogia entre música e narrativa deve ser medida de acordo com as particularidades de cada estudo específico.

3. O grau de interesse intrínseco à própria estrutura narrativa. Trata-se aqui das decisões sobre quais especificidades da narratividade serão consideradas no discurso analítico, desde a presença marcante de narrador e/ou atores antropomórficos e psicológicos até a utilização de um vocabulário literariamente mais neutro, ou seja, que se utilize de termos comuns à teoria musical. Uma vez que a narratividade se encontra fora da música - e embora seu interesse dependa de sua fundamentação na análise musical -, não há necessidade

\footnotetext{
${ }^{7}$ Considero aqui a música em suas representações na performance/gravação e na partitura,
} bem como nas relações intertextuais apontadas por Michael Klein (2004). 
de restringir-se sua extensão ou estilo, ou mesmo suas possíveis versões de uma mesma narrativa.

\section{Uma Trama para o Concerto Grosso n.1 (1977), de Alfred Schnittke}

Figura 1 - Concerto Grosso n.1 de Alfred Schnittke. Estrutura de Movimentos.

1. Preludio

2. Toccata

3. Recitativo

4. Cadenza

5. Rondo

6. Postludio

O ponto de partida na concepção narrativa para o Concerto Grosso n.1 será a identificação do conflito estabelecido entre materiais musicais no decorrer de toda a obra. As duas aparições do piano preparado, uma ao começo e outra ao final do Concerto, emolduram tal conflito de maneira a afetar, mesmo na ausência desse instrumento, a interpretação dos demais eventos musicais. Daí resulta a associação entre o percurso formal da música e a narrativa aqui proposta, cuja efetividade será considerada em relação aos três fatores de relevância estipulados acima. Os fatores a e $b$ serão abordados conjuntamente no decorrer da análise, onde o estabelecimento do vínculo música/narrativa (fator a) é seguido por uma interpretação semântica para os eventos sonoros (fator b); já o fator c será observado nos tipos de designações verbais concebidos especificamente para este trabalho, que neste caso vale-se dos termos entidade musical e processos de intensificação.

O Preludio apresenta o conflito narrativo de maneira fragmentada, permanecendo assim como uma sombra sobre restante do Concerto: seus elementos musicais não servem apenas como referência na identificação de repetições ou transformações posteriores, mas de fato fundamentam a interpretação narrativa aqui proposta. Por esse motivo, passo a apresentar esses 
elementos por ordem de aparição dentro do Preludio, para em seguida relacionálos com a narratividade no Concerto como um todo.

(1) A abertura (Ex. 1) se dá com o piano preparado desacompanhado, o qual expõe uma estrutura musical constituída de duas frases simétricas num movimento harmônico tonal repetido de tônica-dominante-tônica:

Exemplo 1 - Preludio, compassos 1-11.

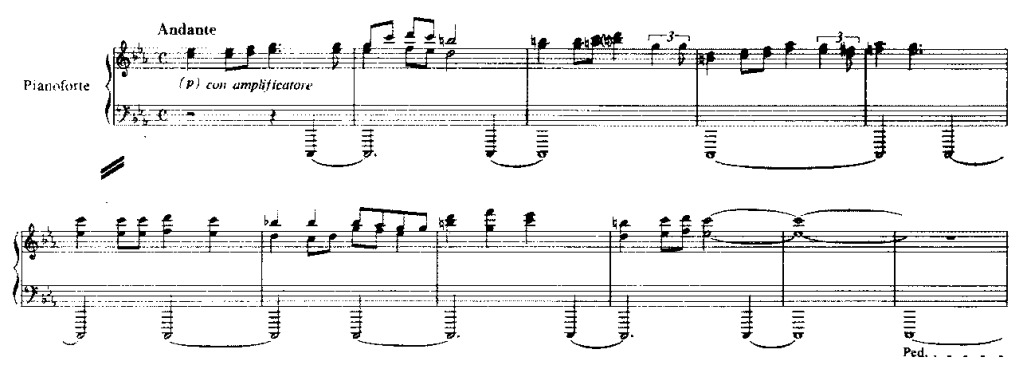

A nota pedal na tônica de dó menor, no registro grave do instrumento, é rearticulada irregularmente e desloca a estrutura métrica da passagem, donde resulta sua perda de direcionalidade e consequente impressão de suspensão. Em sua ligação quase exclusiva com o piano, esta breve abertura está em contraste notável com o restante do Concerto Grosso n.1. Apesar de ser retomada com variações em outros instrumentos, sua repetição literal novamente no piano ao final do Rondo (número de ensaio [26]) torna esse instrumento um agente emblemático para o desfecho narrativo do concerto, como proponho mais adiante.

(2) Por ora, sigamos o curso linear do Preludio, no qual surge a apresentação do concertino (número de ensaio [1]), formado por dois violinos que perfazem, nesse movimento, um crescendo até o final de [6]. Note-se que tal crescendo dá-se não somente em termos de intensidade ( $p p-m f)$, mas traz consigo a ampliação da tessitura em direção ao grave e ao agudo, bem como uma expansão harmônica desde o diatonicismo introduzido pelo piano até o cromatismo acentuado em [6] (Ex. 2): 
Exemplo 2 - Preludio [6], concertino.

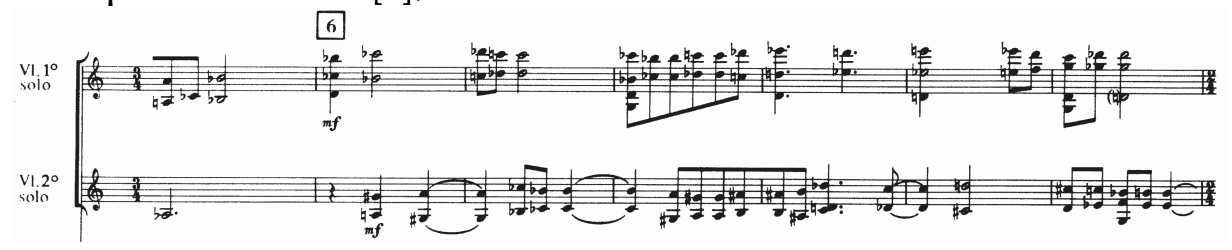

(3) O ripieno (orquestra de cordas) acompanha o crescendo do concertino. Entra com um violoncelo em solo movendo-se entre tônica e dominante com harmônicos naturais ( $p p$, [1]) e conclui o Preludio em tutti com acordes formados por superposições de $9^{\text {as }}$ menores ( $f$, [7]). De certa maneira, a atuação do ripieno funciona também como pontuação estrutural para os dois ápices do concertino ([2] e [6], respectivamente), onde em seguida o ripieno realiza um movimento decrescente de atividade rítmica e de intensidade (cf. [3] e $[7-8])$.

(4) Por fim, observe-se o surgimento do cravo ao final de [3], executando um material composto por intervalos de $9^{\mathrm{a}}$ menor nos registros agudo e grave (Ex. 3), e que, assim como a abertura do piano, será recorrente no concerto (v. g. concertino no Preludio [8], Recitativo [8], e primeiros compassos da Cadenza):

Dada a definição musical objetiva dos itens (1) e (4) na lista acima, considero-os como entidades musicais, no sentido em que sua aparição em determinados momentos do Concerto nos remete diretamente ao Preludio: sua aproximação conceitual, neste caso, sugere uma conjunção piano/cravo (executados pelo mesmo instrumentista) em um personagem bi-facetado na obra, distinto em relação ao concertino e ao ripieno. Sendo assim, o cravo passa a ser a faceta mais híbrida desse personagem, acompanhando os demais instrumentos no Preludio, Toccata e Rondó, e procurando eventualmente inserir o material apresentado pelo piano (item/entidade (1)) de forma mais orgânica nesses movimentos (v. g. Preludio [6], Toccata [12], Rondó [11]).

Por outro lado, os itens (2) e (3) - concernentes a concertino e ripieno retratam antes percursos do que materiais musicais definidos, isto é, referem-se a processos de intensificação rítmica e harmônica (essa última entre os pólos diatônico e cromático), bem como crescendos em intensidade. Com a exceção do 
Postludio, que será considerada mais adiante, esses processos atuam em todos os movimentos do Concerto, fato que thes proporciona um perfil de crescendo entre praticamente cada articulação formal interna; além disso, essa tendência se faz igualmente presente na macro-estrutura de cada movimento.

Exemplo 3 - Preludio, [3], entrada do cravo (em destaque).

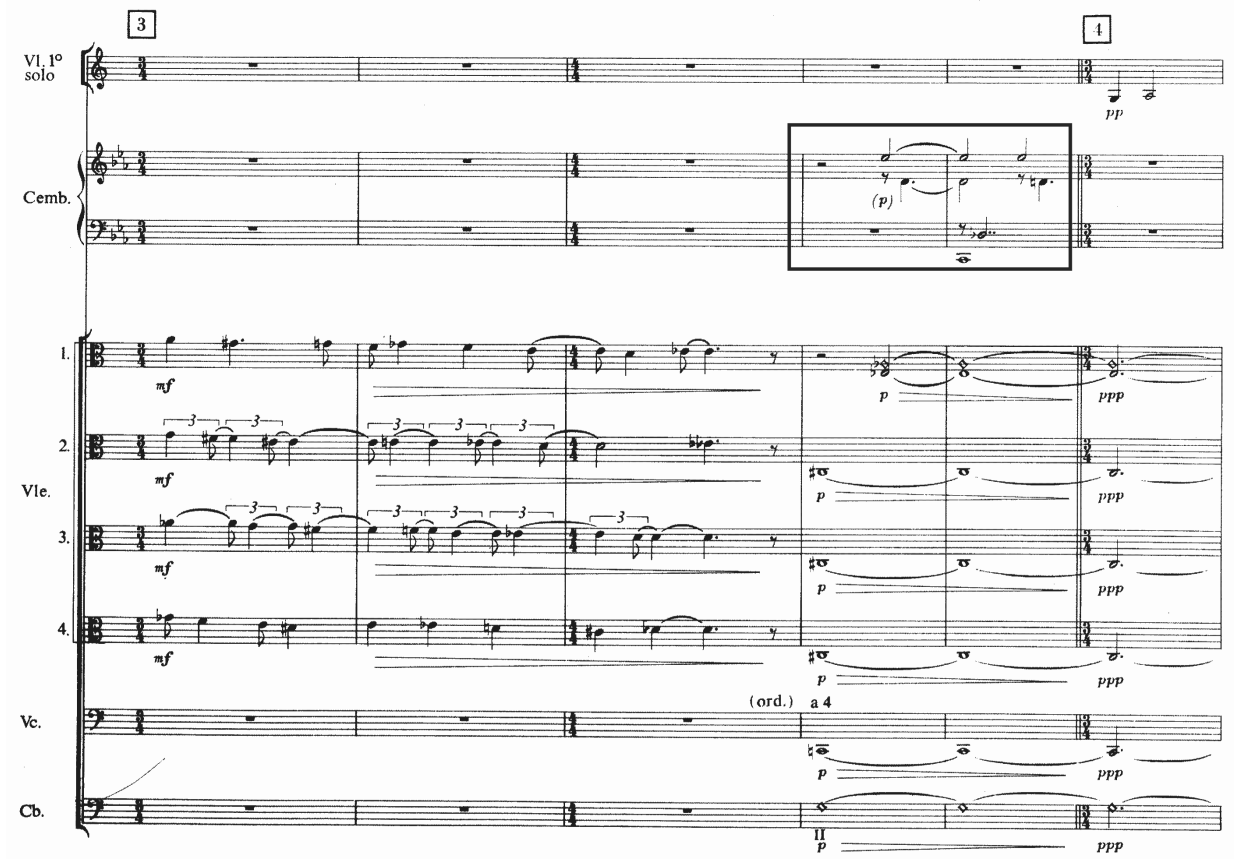

Do contraste entre as aparições do piano (hirto, como entidade musical) com os processos de intensificação (de concertino e ripieno) nasce o conflito em que se baseia a concepção narrativa deste trabalho, a qual permeia a interpretação dos demais movimentos da obra.

Tecnicamente, o emprego de cânones micro-defasados, geralmente com mais de dez vozes e à distância de uma colcheia por entrada (v. Ex. 4), atua em prol dos processos de intensificação de concertino e ripieno (v. g. Toccata [1], [8] e [10]; Recitativo c. 1-12 e [5-9]; Rondo [5], [10] e [18] e [24]). Esse tipo de procedimento é também a principal ferramenta utilizada por Schnittke para "diluir" as referências estilísticas que irrompem ocasionalmente à superfície do Concerto, como no caso dos compassos iniciais da Toccata (Ex. 4): 
Exemplo 4 - Toccata, [1], ripieno, a referência ao estilo barroco desfaz-se gradualmente através do cânone micro-defasado.

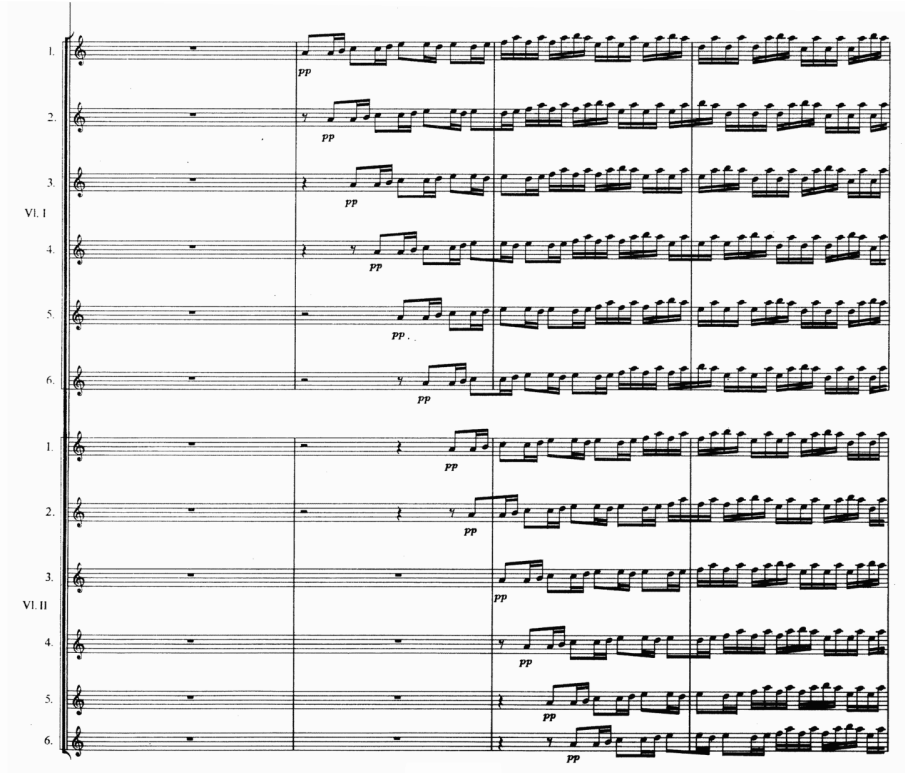

O cravo, espécie de contrapeso numa dupla personalidade do pianista, chega a integrar-se com as cordas na Toccata ( $2^{\circ}$ mov.) e no Rondo ( $5^{\circ}$ mov.). Mas ao interromper repetidamente o Rondo entre [6-7], tocando os intervalos de $9^{\mathrm{a}} \mathrm{m}$ do item (4), nos remete novamente ao Preludio e à introversão característica do piano:

Exemplo 5 - Rondo, [6], interrupção do movimento musical pelo cravo, que executa o material do item (4).

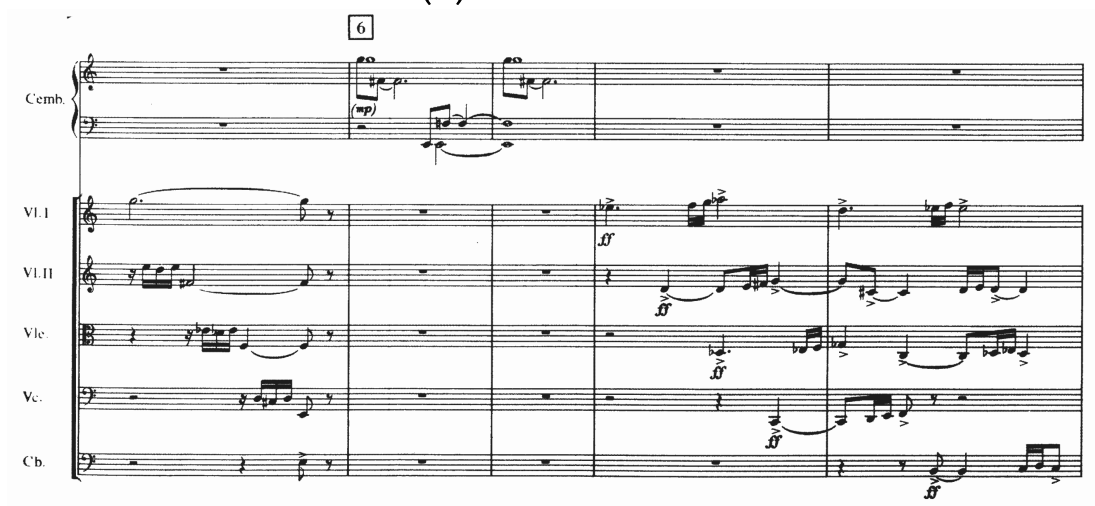


De um modo geral, e apesar dessa intervenção, o conflito narrativo encontra-se provisoriamente reprimido na Toccata e no Rondo, os quais constituem movimentos quase autônomos dentro do Concerto; por outro lado, a direcionalidade do percurso dramático da obra se mantém intercaladamente através do Recitativo, da Cadenza e do Postludio. Sendo, portanto, duas peças aparentemente alheias ao conflito narrativo que permeia a obra, é na Tocata e no Rondo que surgem explicitamente referências a outras realidades musicais, principalmente ao período barroco (v. g. Tocata [1] e [6-8]; Rondo [1-4]). Através dessas referências, esses dois movimentos são momentos em que a obra olha para fora de si mesma, arejando suas próprias perturbações: o tango executado no meio do Rondo (cf. [13-15]) é, sob essa perspectiva, particularmente significativo por sua duração longa e distância estilística acentuada em relação aos demais materiais da peça:

Exemplo 6 - Rondo [13], tango executado por cravo e concertino.

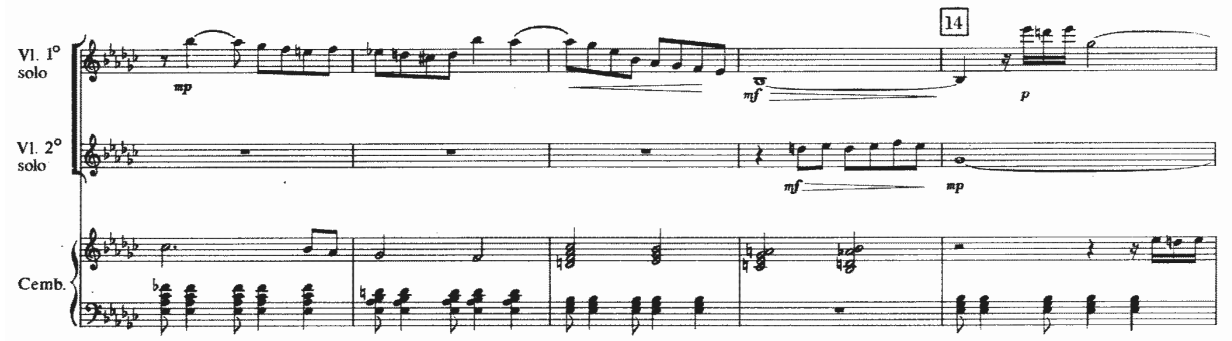

Entretanto, dado o contexto em que estão inseridos, esses olhares externos possuem uma particularidade dramática: os cânones da orquestra continuam sempre presentes, e sua ressonância cumulativa gera clusters estendidos no tempo que, inclusive no tango (cf. [15-17]), desfazem as referências e as reconduzem à peça. Sendo assim, tais referências externas podem ser consideradas também como desvarios psicológicos, transtornados e obcecados pela repressão de um conflito virtualmente onipresente, o qual pode ressurgir a qualquer momento, como no caso da supracitada interrupção do cravo (Ex. 5).

Além disso, há que se considerar que a Toccata e o Rondo estão separados no tempo pelo Recitativo e pela Cadenza, os quais desenvolvem os processos de intensificação de concertino e ripieno. No Recitativo, o ripieno 
recomeça o movimento do Preludio, interrompido pela Tocata, expandindo-o juntamente com o concertino. Embora essa expansão não seja constante e linear, havendo nela alguns momentos internos de recolhimento textural e de intensidade (v. g. [2]), ela atinge seu apogeu justamente no final do Recitativo ([11]), com a aceleração rítmica, o aumento de divisi e o direcionamento para o registro extremo-agudo através de glissandi. O resultado dessa condução é a Cadenza, onde concertino, desacompanhado, detém-se nas notas duplas de ataques marcados, à maneira do Preludio. A estaticidade harmônica e a fragmentação da música - através de silêncios entre as intervenções violinísticas -, conferem à Cadenza um caráter de suspensão que contrasta com o movimento musical constante no resto do Concerto, aproximando-a nesse sentido da abertura da obra, realizada pelo piano: em ambos os casos, o material musical é restrito e parece ignorar qualquer realidade alheia à sua própria identidade; a Cadenza é, assim, o momento de maior vigor do concertino na obra, numa suspensão do tempo capaz de simultaneamente referenciar e contrapor-se à coesão da entidade piano. É essa força que permite ao concerto uma derradeira renovação no extrovertido e veloz Rondo, introduzido pelos solistas numa cadência operística com acorde napolitano:

Exemplo 7 - Cadenza [5], transição ao Rondo através de cadência com acorde napolitano.

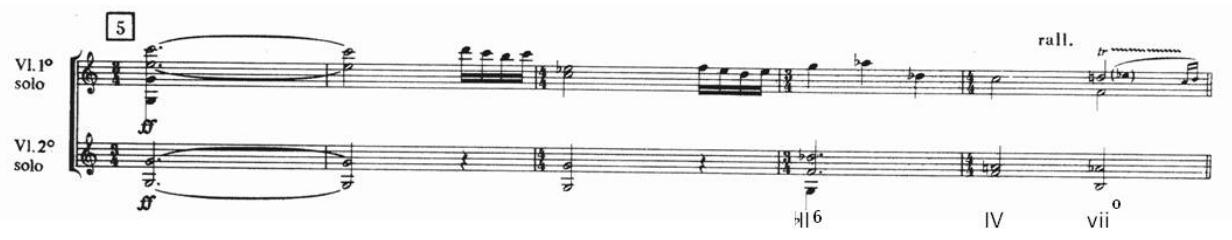

Não obstante a isso, o desenlace trágico do Concerto revelar-se-á enfim na conclusão do Rondo, marcado pela reaparição do piano em [26], numa repetição literal da estrutura musical com a qual abriu a obra (Ex. 1). Sua re-entrada dá-se num momento crucial, quando os demais instrumentos repetem o fim da cadenza (Ex. 7) numa versão orquestrada em tutti, com o concertino tocando oitava acima e sob dinâmica fff. A expectativa, nessa conclusão do Rondo, é a de realização plena do movimento, onde os processos de intensificação das cordas parecem 
chegar ao momento em que atingirão seu objetivo, impondo sua predominância sobre o conflito narrativo da obra ${ }^{8}$.

O piano, portanto, surge como invasor e destruidor, transformando drasticamente o destino da peça, e submetendo os demais instrumentos imediatamente a um plano secundário. Assim, a orquestra se dirige em decrescendo ao registro agudo, posição que manterá durante todo o Postludio, com sonoridades menos marcantes em harmônicos e sul ponticello - embora ainda assim com um impulso pontual de recomeço da Toccata (Postludio [1], c. 68), o qual é prontamente abafado pelo piano ([2]), que estabelece definitivamente sua posição hierárquica dominante, na qual o Concerto é finalizado.

A narrativa proposta neste trabalho pode ser sintetizada graficamente da seguinte maneira:

Figura 2 - Esquema narrativo para o Concerto Grosso n.1.

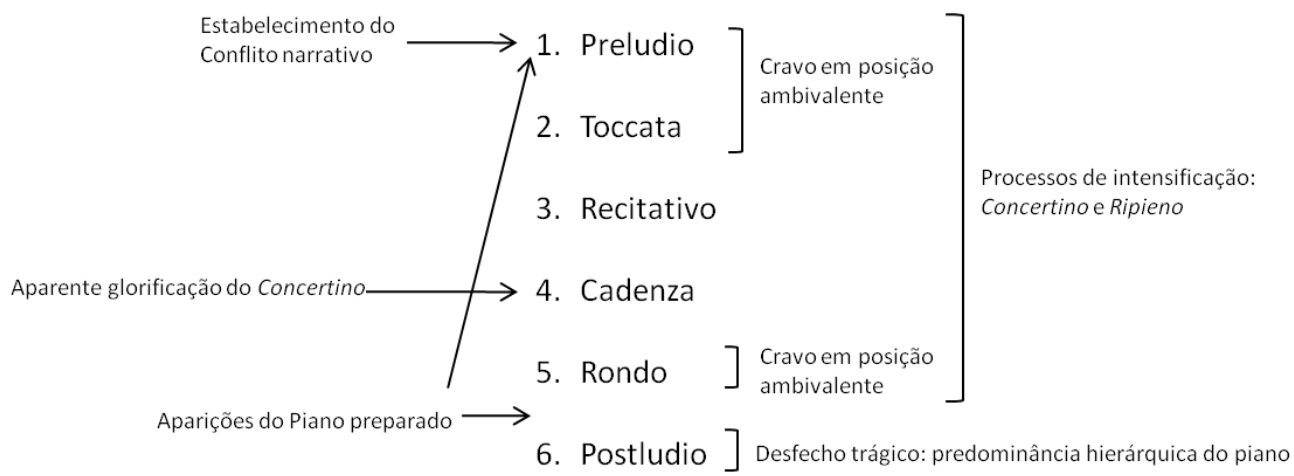

\footnotetext{
${ }^{8}$ Embora não haja sido feita aqui uma aproximação teórica, considero que a designação "trágico" coincide, neste caso específico, com sua definição nos Arquétipos Narrativos propostos por Almén (2003 p. 11-20, e 2008 p. 64-67), ou seja: a reaparição definitiva do piano marca para o concertino sua descida desde a fortuna em direção à catástrofe. Esta idéia, com origem na Poética de Aristóteles, foi adaptada para a análise musical por Almén a partir de teorias literárias de Northrop Frye (cf. Almén 2003, p. 14-15).
} 


\section{Considerações Finais}

Ao atribuir ao Concerto Grosso n.1 de Schnittke uma trama narrativa, este trabalho apresentou uma possível leitura da obra, ou seja, não se propôs a uma análise explicativa que esgote o fenômeno musical; por outro lado, acredito que uma parcela significativa do conteúdo do Concerto está reproduzida na trama apresentada, que ao atribuir causalidade aos eventos sonoros, busca dar sentido semântico ao seu desenrolar temporal, bem como a elementos pontuais; esse último, por exemplo, é o caso do distúrbio de personalidade piano/cravo, onde o último assume uma posição de meio termo no conflito narrativo. Há que se considerar, em todo o caso, que essa trama concebe para a obra um plano atemporal e abstrato - embora esteja fundamentada nas relações referenciais com materiais musicais e apropriações estilísticas -, podendo ser narrada verbalmente de maneiras ilimitadas em quantidade e extensão. Certamente, o Concerto em sua performance transcende essa realidade e potencializa outras associações que são alheias ao plano proposto; mas a trama, não sendo a música, pode também adaptar-se e abranger ou mesmo criar outras associações: sua narrativa também transcende a música.

\section{Referências}

AGAWU, V. Kofi. Playing With Signs: A Semiotic Interpretation of Classical Music. New Jersey: Princeton University Press, 1991.

ABBATE, Carolyn. Unsung Voices: Opera and Musical Narrative in the Nineteenth Century. New Jersey: Princeton University Press, 1991.

ALMÉN, Byron. Narrative Archetypes: A Critique, Theory, and Method of Narrative Analysis. Journal of Music Theory, New Haven, vol. 47 no. 1, p. 1-39, 2003.

Press, 2008.

. A Theory of Musical Narrative. Bloomington: Indiana University

GRABÓCZ, Márta. Stratégies narratives des “epopées philosophiques” de l'ere romantique dans l'œvre pianistique de F. Liszt. Studia Musicologica Scientiarium Hungaricae, Akadémiai Kiadó, T. 28, Fasc. 1/4, p. 99-115, 1986. 
HATTEN, Robert. On Narrativity in Music: Expressive Genres and Levels of Discourse in Beethoven. Indiana Theory Review, Bloomington, vol. 12, p. 76-98, 1991.

KARL, Gregory. Structuralism and Musical Plot. Music Theory Spectrum, University of California Press, vol. 19 no. 1, p. 13-34, spring 1997.

KLEIN, Michael. Intertextuality in Western Art Music. Bloomington: Indiana University Press, 2004.

KRAMER, Lawrence. Musical Narratology: A Theoretical Outline. Indiana Theory Review, Bloomington, vol. 12, p. 142-162, 1991.

MAUS, Fred E. Music as Narrative. Indiana Theory Review, Bloomington, vol. 12, p. 142-162, 1991.

MICZNIK, Vera. Music and Narrative Revisited: Degrees of Narrativity in Beethoven and Mahler. Journal of the Royal Musical Association, Vol. 126, No. 2 (2001), pp. 193-249

MONELLE, Raymond. Structural Semantics and Instrumental Music. Music Analysis, vol. 10 No. 1/2, p. 73-88, 1991.

NATTIEZ, Jean-Jacques. Can One Speak of Narrativity in Music? Journal of The Royal Musical Association, vol. 115 No. 2, p. 240-257, 1990a.

. Music And Discourse: Toward a Semiology of Music. New Jersey:

Princeton University Press, $1990 \mathrm{~b}$.

- O Combate entre Cronos e Orfeu: Ensaios de semiologia musical aplicada. São Paulo: Via Lettera Editora, 2005.

SCHNITKKE, Alfred. Concerto Grosso. Viena: Universal Editions, 1977.

TARASTI, Eero. A Theory of Musical Semiotics. Bloomington: Indiana University Press, 1994. 